\title{
Distinct Corticospinal and Reticulospinal Contributions to Voluntary Control of Elbow Flexor and Extensor Muscles in Humans with Tetraplegia
}

\author{
Sina Sangari and Monica A. Perez \\ Shirley Ryan AbilityLab, Chicago, Illinois, Department of Physical Medicine and Rehabilitation, Northwestern University, Chicago, Illinois, 60611, \\ and Edward Hines Jr. VA Hospital, Hines, Illinois, 60141
}

\begin{abstract}
Humans with cervical spinal cord injury (SCI) often recover voluntary control of elbow flexors and, to a much lesser extent, elbow extensor muscles. The neural mechanisms underlying this asymmetrical recovery remain unknown. Anatomical and physiological evidence in animals and humans indicates that corticospinal and reticulospinal pathways differentially control elbow flexor and extensor motoneurons; therefore, it is possible that reorganization in these pathways contributes to the asymmetrical recovery of elbow muscles after SCI. To test this hypothesis, we examined motor-evoked potentials (MEPs) elicited by transcranial magnetic stimulation over the arm representation of the primary motor cortex, maximal voluntary contractions, the StartReact response (a shortening in reaction time evoked by a startling stimulus), and the effect of an acoustic startle cue on MEPs elicited by cervicomedullary stimulation (CMEPs) on biceps and triceps brachii in males and females with and without chronic cervical incomplete SCI. We found that SCI participants showed similar MEPs and maximal voluntary contractions in biceps but smaller responses in triceps compared with controls, suggesting reduced corticospinal inputs to elbow extensors. The StartReact and CMEP facilitation was larger in biceps but similar to controls in triceps, suggesting enhanced reticulospinal inputs to elbow flexors. These findings support the hypothesis that the recovery of biceps after cervical SCI results, at least in part, from increased reticulospinal inputs and that the lack of these extra inputs combined with the loss of corticospinal drive contribute to the pronounced weakness found in triceps.
\end{abstract}

Key words: biceps; corticospinal; humans; reticulospinal; spinal cord injury; triceps

Significance Statement

Although a number of individuals with cervical incomplete spinal cord injury show limited functional recovery of elbow extensors compared with elbow flexor muscles, to date, the neural mechanisms underlying this asymmetrical recovery remain unknown. Here, we provide for the first time evidence for increased reticulospinal inputs to biceps but not triceps brachii and loss of corticospinal drive to triceps brachii in humans with tetraplegia. We propose that this reorganization in descending control contributes to the asymmetrical recovery between elbow flexor and extensor muscles after cervical spinal cord injury.

\section{Introduction}

Spinal cord injury (SCI) often results in decreased voluntary control of muscles below the level of injury. In individuals with cervical lesions, limited functional recovery has been reported in

Received May 8, 2020; revised Aug. 20, 2020; accepted Aug. 27, 2020.

Author contributions: S.S. and M.A.P. designed research; S.S. and M.A.P. performed research; S.S. and M.A.P. contributed unpublished reagents/analytic tools; S.S. and M.A.P. analyzed data; S.S. and M.A.P. wrote the first draft of the paper; S.S. and M.A.P. edited the paper; S.S. and M.A.P. wrote the paper.

M.A.P. was supported by the National Institute of Neurological Disorders and Stroke and the Department of Veterans Affairs. S.S. was supported by the Craig H. Neilsen Foundation.

The authors declare no competing financial interests.

Correspondence should be addressed to Monica A. Perez at mperez04@sralab.org.

https://doi.org/10.1523/JNEUROSCI.1107-20.2020

Copyright $\odot 2020$ the authors elbow extensors compared with elbow flexor muscles (Ditunno et al., 1992, 2000; Calancie et al., 2004; McKay et al., 2011). This is interesting considering that the location of corticospinal projections (Penfield and Boldrey, 1937) and motoneurons (Schirmer et al., 2011) that innervate these muscles largely overlap, and that most injuries to the cervical spinal cord affect more than one spinal segment (Schaefer et al., 1989; Benavides et al., 2020). Loss of motoneurons near the injury site (Grumbles and Thomas, 2017), alterations in motor unit recruitment patterns and muscle atrophy (Thomas et al., 1997a,b, 1998; Johanson et al., 2013) might contribute to the poor recovery in triceps brachii. However, it is likely that other factors are involved in the asymmetrical recovery between elbow flexor and extensor muscles after SCI. 
Anatomical and electrophysiological studies have shown that elbow flexors and extensors receive differential control from corticospinal and reticulospinal pathways. For example, the terminal distribution of crossed and ipsilateral corticospinal projections to interneurons and motoneurons is larger in biceps compared with triceps brachii (Morecraft et al., 2013). In monkeys (Phillips and Porter, 1964; McKiernan et al., 1998) and humans (Palmer and Ashby, 1992; de Noordhout et al., 1999), elbow flexor motoneurons receive large corticospinal monosynaptic facilitation, whereas triceps motoneurons receive lesser monosynaptic facilitation but strong disynaptic inhibition. Reticulospinal axons are bilaterally distributed with a majority of ipsilateral axons in monkeys and humans (Nathan et al., 1996; Sakai et al., 2009). Stimulation of the reticular formation in monkeys produced biceps facilitation and triceps suppression ipsilaterally (Davidson and Buford, 2006; Davidson et al., 2007; Herbert et al., 2010; Hirschauer and Buford, 2015), consistent with findings in humans showing that ipsilateral cortico-reticulospinal responses are more easily observed in biceps compared with triceps brachii (Ziemann et al., 1999).

Both corticospinal (Oudega and Perez, 2012) and reticulospinal (Asboth et al., 2018) pathways undergo reorganization after SCI, which might then contribute to the asymmetrical recovery reported in elbow extensors compared with elbow flexor muscles. Corticospinal inputs are largely decreased in triceps brachii in humans with incomplete cervical SCI compared with control subjects (Thomas et al., 1997b). Corticospinal lesions in primates led to enhanced monosynaptic and disynaptic reticulospinal facilitation to forearm flexors compared with extensor muscles (Zaaimi et al., 2012), and reticulospinal neurons may have a greater response to regeneration approaches than corticospinal neurons (Vavrek et al., 2007; Zörner et al., 2014). Thus, we hypothesized that reduced corticospinal inputs to triceps brachii and increased reticulospinal inputs to biceps brachii contribute to the asymmetrical recovery observed in people with cervical incomplete SCI.

To test this hypothesis, we examined motor-evoked potentials (MEPs) elicited from the arm representation of the primary motor cortex, maximal voluntary contractions (MVCs), the StartReact response (a shortening in reaction time evoked by a startling stimulus), and the effect of an acoustic startle cue on an MEP elicited by cervicomedullary stimulation (cervicomedullary MEPs [CMEPs]) in biceps and triceps brachii of individuals with and without cervical SCI.

\section{Materials and Methods}

Subjects. Eighteen individuals with SCI (mean age $43.3 \pm 16.1$ years, 2 female; Table 1) and 15 age-matched controls (mean age $40.1 \pm$ 14.2 years, 4 female, $p=0.7$ ) participated in the study. All participants gave informed consent to the experimental procedures, which were approved by the local ethics committee at Northwestern University and performed in accordance with the Declaration of Helsinki. Participants with SCI had a chronic injury ( $\geq 1$ year) and were classified using the International Standards for Neurological Classification of Spinal Cord Injury examination as having a C1-C6 SCI and by the American Spinal Cord Injury Association Impairment Scale (AIS) as AIS A $(n=4)$, AIS C $(n=10)$, and AIS D $(n=4)$. We tested individuals with preservation of motor output in the biceps and triceps brachii to assess the contribution of residual descending motor pathways. All subjects were asked to perform voluntary elbow flexion and extension, and all of them were able to exert voluntary EMG activity in the biceps and triceps muscles. Nine SCI individuals were under antispastic medication (baclofen and/or gabapentin and/or tizanidine; Table 1). However, none of them showed spasticity in their biceps and triceps brachii, as examined with the Modified Ashworth Scale (MAS $=0$ ).
Table 1. SCI participants ${ }^{\mathrm{a}}$

\begin{tabular}{llllllll}
\hline Participant no. & Age (yr) & Gender & AlS & Level & Etiology & Time after injury (yr) & Medication(s) \\
\hline 1 & 31 & M & A & C5 & T & 12 & None \\
2 & 62 & M & D & C5 & T & 17 & None \\
3 & 27 & M & A & C1 & T & 4 & BAC \\
4 & 34 & F & C & C4 & T & 16 & None \\
5 & 71 & M & C & C2 & T & 8 & BAC \\
6 & 38 & M & C & C5 & T & 3 & BAC \\
7 & 62 & M & D & C1 & NT & 5 & GBP \\
8 & 69 & M & C & C2 & T & 11 & GBP, TIZ \\
9 & 47 & M & C & C5 & T & 3 & BAC \\
10 & 33 & M & C & C5 & T & 6 & None \\
11 & 29 & M & A & C4 & T & 3 & None \\
12 & 22 & M & A & C5 & T & 2 & BAC \\
13 & 48 & M & D & C6 & T & 12 & None \\
14 & 27 & M & C & C4 & T & 8 & BAC, GBP \\
15 & 50 & M & D & C5 & T & 1 & BAC, GBP \\
16 & 24 & M & C & C5 & NT & 1 & None \\
17 & 60 & F & C & C5 & T & 36 & None \\
18 & 45 & M & C & C4 & T & 11 & None \\
\hline
\end{tabular}

${ }^{a}$ T, traumatic; NT, nontraumatic; BAC, baclofen; GBP, gabapentin; TIZ, tizanidine.

EMG recordings. EMG was recorded from the right biceps and triceps brachii in control subjects and from the less affected side in individuals with SCI through bipolar surface electrodes $(\mathrm{Ag}-\mathrm{AgCl}, 10 \mathrm{~mm}$ diameter, $1 \mathrm{~cm}$ apart) secured on the skin. Signals were amplified, filtered $(30-2000 \mathrm{~Hz})$, and sampled at $2 \mathrm{kHz}$ for offline analysis (CED 1401 with Signal software, Cambridge Electronic Design).

Experimental paradigm. During testing, subjects were seated comfortably in an armchair with their arm supported by a custom platform. The tested arm was positioned with the shoulder and the elbow flexed at $90^{\circ}$ and strapped to the platform. During MVCs, subjects were instructed to perform an isometric elbow flexion for biceps MVC and an elbow extension for triceps MVC. Subjects performed three brief MVCs for 3-5 s for both elbow flexion and elbow extension, separated by $\sim 1$ min of rest. The maximal mean EMG activity of the rectified response generated for $1 \mathrm{~s}$ during each MVC was analyzed, and the highest value of the three trials was used. MVCs were tested at the beginning of the session followed by examination of MEP recruitment curves, Mmax, StartReact, and CMEPs.

MEP recruitment curves. Transcranial magnetic stimulation (TMS) was delivered over the arm representation of the primary motor cortex from a BiStim ${ }^{2}$ (Magstim) through a circular coil with a monophasic current waveform. The coil was positioned at the optimal site for eliciting an MEP in the contralateral biceps and triceps muscles during a small tonic voluntary contraction of $\sim 10 \%$ of the MVC (biceps: controls $=7.0 \pm 0.5 \%$ of the MVC, SCI $=7.1 \pm 0.9 \%$ of the MVC, $U=124.0, p=0.7, r=0.07$; triceps: controls $=7.1 \pm 0.6 \%$ of the MVC, $\mathrm{SCI}=7.9 \pm 2.4 \%$ of the MVC, $U=106.0, p=0.3, r=0.2)$. Participants wore a cap on which the position of the coil was marked to ensure the stability of TMS across measurements. The TMS intensity ranged from below the active motor threshold (AMT) to the intensity needed to produce a maximal MEP (MEP-max), increasing by $5 \%$ increments until the maximal stimulator output (MSO) was reached. The AMT was defined as the minimal stimulus intensity needed to elicit 5 of $10 \mathrm{MEPs}$ $100 \mu \mathrm{V}$ above the EMG background. Ten stimuli (interstimulus interval: $0.2 \mathrm{~Hz}$ ) were delivered at each intensity to plot the mean peak-to-peak amplitude of the MEP from the nonrectified response against the TMS intensity in each subject (MEP recruitment curve; Fig. $1 A$ ). The experimental data were fitted with the following 3-parameter sigmoid function (Devanne et al., 1997; Carroll et al., 2001):

$$
M E P=\frac{\text { MEP-max }}{1+e^{\frac{I_{50}-I}{k}}}
$$

where MEP-max is the maximal amplitude of the MEP, $I_{50}$ is the TMS intensity producing half MEP-max, and $k$ is the Boltzmann slope 

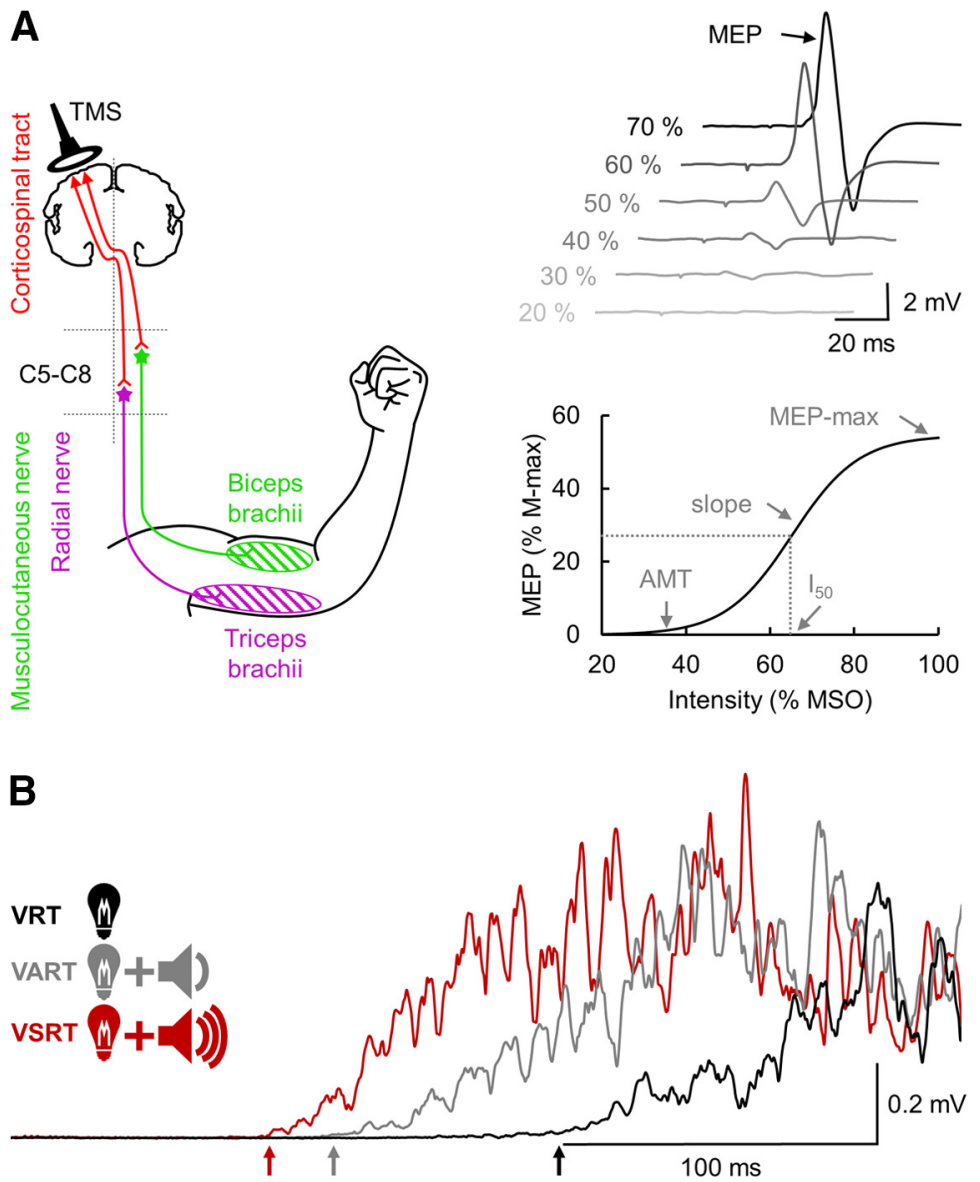

Figure 1. Experimental setup. A, TMS was applied over the arm representation of the primary motor cortex to activate corticospinal neurons projecting directly or indirectly to biceps and triceps brachii motoneurons located between the fifth and the eighth cervical segment (C5-(8) to elicit an MEP. MEP recruitment curve was constructed by plotting the amplitude of the MEP against the TMS intensity and allow to define the MEP-max, $I_{50}$, AMT, and the slope of the curve. $\boldsymbol{B}$, During the StartReact response in some trials, an LED was presented with either an auditory acoustic stimulus or a SAS. The StartReact response was measured between the VRT (defined as the time from cue to onset of the EMG burst in the biceps and triceps brachii after the LED presentation), the VART (defined as the time delay between the presentation of the auditory acoustic stimulus and the EMG onset), and the VSRT (defined as the time between the SAS and the EMG onset).

parameter (Fig. 1A). Sigmoid fit was individually performed for each subject. The estimated values of each parameter of the sigmoid (MEP$\max , I_{50}$ and $k$ ) were extracted for each participant, and the mean of each parameter was calculated for both control and SCI participants. The mean estimated MEP-max, $I_{50}$, and $k$ were used to draw the mean estimated sigmoid curve for each group. MEP-max onset latencies were defined as the time when the rectified EMG reached $2 \times \mathrm{SD}$ calculated over a $100 \mathrm{~ms}$ period of the prestimulus activity of the MEP with the largest amplitude in each participant. Percutaneous electrical stimulation of the brachial plexus was delivered $(1 \mathrm{~ms}$ rectangular electrical stimulus, DS7AH, Digitimer) through a cathode (10-mm-diameter Ag-AgCl electrode) placed over the Erb point and an anode ( $\mathrm{Ag}-\mathrm{AgCl}$ plaque) placed over the shoulder. The M-max was obtained by increasing the stimulus intensity until no increases in the M-wave amplitude were observed. Two pulses were used at each stimulus intensity (interstimulus interval: $0.2 \mathrm{~Hz}$ ). The M-max was measured as the peak-to-peak amplitude of the nonrectified response, and it was used to normalize MEP values in each participant.

StartReact response. The StartReact response was tested using a previously described paradigm in humans with SCI (Baker and Perez, 2017). Here, participants were asked to observe an LED located $\sim 1 \mathrm{~m}$ in front of the participant's head. When the LED was illuminated $(20 \mathrm{~ms})$, individuals were asked to perform an isometric elbow flexion or an isometric elbow extension as fast as possible. We measured the visual reaction time (VRT; Fig. $1 B$ ) as the time from cue to onset of the EMG burst in the targeted muscle after the LED presentation. The reaction time was defined as the time point when the rectified EMG signal exceeded $2 \times \mathrm{SD}$ calculated over a $100 \mathrm{~ms}$ period of the prestimulus activity. In some trials, the LED was presented with either a quiet acoustic stimulus $(80 \mathrm{~dB}, 500 \mathrm{~Hz}, 50 \mathrm{~ms})$ or a startling acoustic stimulus (SAS, $120 \mathrm{~dB}, 500 \mathrm{~Hz}, 50 \mathrm{~ms}$ ) delivered through two audio speakers (T-15, Polk Audio) located right behind the participant's head. The loud intensity evoked a clear startle in control subjects and in some individuals with SCI on initial presentation. The time delay between the presentation of the quiet acoustic stimulus and the onset of the EMG response was defined as the visual-auditory reaction time (VART; Fig. $1 B)$, whereas the time between the SAS and the EMG onset was defined as the visual-startle reaction time (VSRT; Fig. 1B). A familiarization trial consisting of three repetitions of each task responding to the LED was completed at the beginning of each experiment to ensure that participants were able to complete all tasks and to familiarize them with the startling cue (Fisher et al., 2013). In each task, 20 responses (interstimulus interval: $0.2 \mathrm{~Hz}$ ) were recorded for each condition (VRT, VART, and VSRT) in a randomized order. Data were measured trial by trial. Reaction times exceeding $700 \mathrm{~ms}$ were excluded. The VART and VSRT are both mediated via the cochlear nuclei, but only the high-intensity sound of the VSRT activates the reticulospinal pathway (Davis et al., 1982; Brown et al., 1991; Valls-Solé et al., 1999). To estimate changes in the gain of the reticulospinal output, we normalized the data as follows (Baker and Perez, 2017):

$$
\text { Reticulospinal Gain }=\frac{V R T-V S R T}{V R T-V A R T}=\frac{\Delta \mathrm{TSR}}{\Delta \mathrm{TAR}}
$$

where $\Delta$ TSR (i.e., shortening of reaction time with a startle stimulus) is the shortening effect of a SAS on the VRT, and $\triangle \mathrm{TAR}$ (i.e., shortening of reaction time with an auditory stimulus) measures the shortening of reaction time provided by a nonstartling auditory stimulus on the VRT, which presumably does not activate reticulospinal pathways.

CMEPs. The corticospinal tract was stimulated by highvoltage electrical current (200 $\mu$ s duration, DS7AH, Digitimer) passed between two electrodes ( $\mathrm{Ag}-\mathrm{AgCl}, 10 \mathrm{~mm}$ diameter) fixed to the skin behind each mastoid process at the cervicomedullary level (Taylor and Gandevia, 2004). The effect of an SAS on CMEP size was tested using previously described methods (Furubayashi et al., 2000). It has been demonstrated that an acoustic startle cue preceding an MEP by $80 \mathrm{~ms}$ increases the size of the MEP at a subcortical level (Furubayashi et al., 2000; Kühn et al., 2004; Ilic et al., 2011; Tazoe and Perez, 2017). A test stimulus (CMEP-test) was delivered at an intensity that elicited a CMEP in the biceps or triceps muscles of $\sim 1 \mathrm{mV}$ during a tonic contraction of the respective muscle at $\sim 10 \%$ of the MVC (biceps: controls $=8.4 \pm 1.2 \%$ of the MVC, $\mathrm{SCI}=8.0 \pm 1.1 \%$ of the MVC, $t_{(22)}=0.8, p=0.4, d=0.3$; triceps: controls $=8.4 \pm 1.2 \%$ of the MVC, SCI $=8.6 \pm 1.0 \%$ of the MVC, $t_{(22)}=$ $0.4, p=0.7, d=0.2$ ). A conditioning stimulus (SAS, $120 \mathrm{~dB}, 500 \mathrm{~Hz}, 50 \mathrm{~ms}$; CMEP-startle) was presented $80 \mathrm{~ms}$ before a test stimulus through two audio speakers (T-15, Polk Audio) located right behind the participant's head. Three consecutive acoustic stimuli were presented at the beginning of each experiment to ensure that participants were familiarized with the startling cue. Ten responses (interstimulus interval: $0.25 \mathrm{~Hz}$ ) were recorded in each condition (CMEP-test, CMEP-startle) in a randomized order. Note that similar results were found when we used an interstimulus interval of $0.05 \mathrm{~Hz}$. CMEPs were measured in 12 control and $12 \mathrm{SCI}$ participants randomly selected from each group. The CMEP was measured as the peak-to-peak amplitude of the nonrectified response. The CMEP onset 

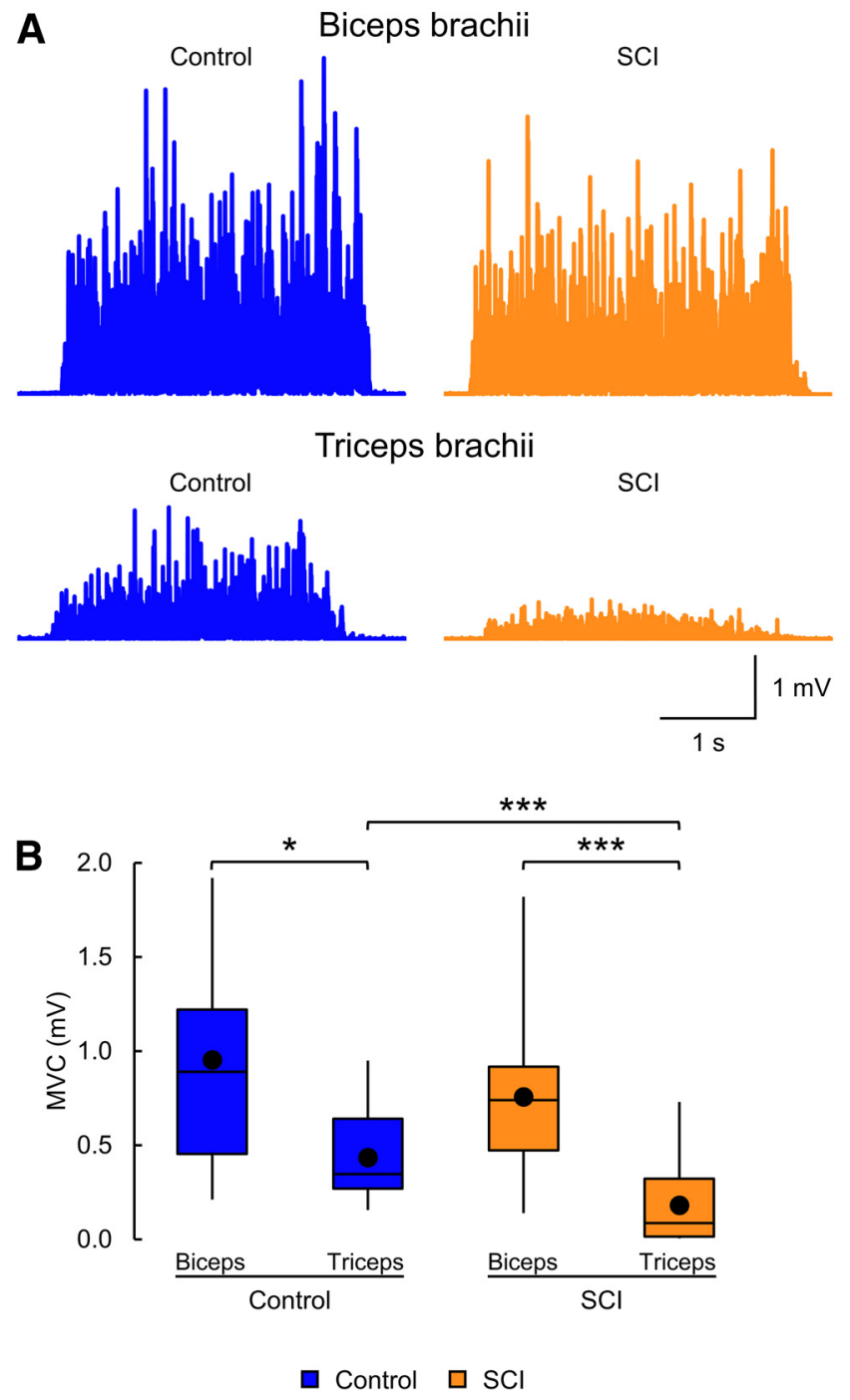

Figure 2. MVCs. $A$, EMG recorded during biceps and triceps brachii MVCs in a control subject (blue) and a participant with SCI (orange). The SCI participant exhibited similar biceps MVC, but smaller triceps MVC, compared with the control subject. $B$, Box plot charts represent the group data. Abscissa indicates the groups tested (blue bars represent the control group; orange bars represent the $\mathrm{SCl}$ group). Ordinate indicates the MVC (in millivolts). Top and bottom lines of the box indicate the 75th percentile (top quartile) and 25th percentile (bottom quartile), respectively. Line in the box indicates the 50th percentile (median). The two bars extend from the maximum and minimum value. Dot within the box indicates the arithmetical mean. ${ }^{*} p<0.05,{ }^{* * *} p<0.001$.

latencies were defined when the rectified EMG reached $2 \times$ SD calculated over a $100 \mathrm{~ms}$ period of the prestimulus activity.

Data analysis. Normal distribution was tested by the Shapiro-Wilk's test and homogeneity of variances was tested by the Levene's test of equality and Mauchly's test of sphericity. When sphericity could not be assumed, the Greenhouse-Geisser correction statistic was used. Twoway ANOVA was performed to determine the effect of group (control, SCI) and muscle (biceps, triceps) on MVCs, CMEPs, and the reticulospinal gain. Repeated-measures ANOVAs as a mixed model were also performed to determine the effect of group and condition (VRT, VART, VSRT) on reaction times and on the mean EMG activity measured over $100 \mathrm{~ms}$ before stimulus and during EMG burst. Condition was used as a repeated-measures factor. Additional repeated-measures ANOVAs were performed on each group separately as needed. The Holm-Sidak adjustment was used to correct all post hoc comparisons. A Student's $t$ test was performed to compare the difference between group or muscle on the voluntary level of contraction exerted during MEP recruitment curves and CMEPs, the MEP-max, slope, AMT, M-max, and between SCI individuals taking and not taking antispastic medications. Pearson correlation coefficient analysis was used as needed. If data were not normally distributed, a log transformation was applied. Normality was retested after the log transformation: if normality was confirmed, a parametric analysis was performed; otherwise, a nonparametric analysis (MannWhitney $U$ test) was completed. Statistical analyses were conducted using SigmaPlot (Systat Software), with the significance set at $p<0.05$. Group data are presented as mean \pm SD.

\section{Results}

MVC

Figure $2 A$ illustrates the rectified EMG activity in biceps and triceps during an MVC in a control (blue) and a SCI (orange) participant. The SCI participant showed similar MVC in biceps but smaller MVC in triceps compared with the control subject. Two-way ANOVA showed an effect of group $\left(F_{(1,62)}=14.6, p<0.001\right)$ and muscle $\left(F_{(1,62)}=36.4, p<0.001\right)$ and in their interaction $\left(F_{(1,62)}=\right.$ $8.1, p=0.006$ ) on MVC (Fig. 2B). Post hoc tests showed that MVCs were reduced in triceps compared with biceps in control (biceps $=1.0 \pm 0.5 \mathrm{mV}$, triceps $=0.4 \pm 0.2 \mathrm{mV}, t_{(28)}=2.2, p=0.03$, $d=1.6$ ) and SCI (biceps $=0.8 \pm 0.4 \mathrm{mV}$, triceps $=0.2 \pm 0.2 \mathrm{mV}, t_{(34)}$ $=6.6, p<0.001, d=1.9)$ participants. Post hoc tests also showed that biceps MVCs were not different between control and SCI groups $\left(t_{(31)}=0.7, p=0.5, d=0.4\right)$, but that triceps MVCs were smaller in SCI compared with controls $\left(t_{(31)}=4.7, p<0.001\right.$, $d=1.0$ ). Within the SCI group, MVC values remained similar between participants taking and not taking antispastic medications (biceps, $t_{(16)}=1.0, p=0.3, d=0.5$; triceps $t_{(16)}=0.3, p=0.8, d=0.1$ ).

\section{MEP recruitment curves}

Figure $3 A$ illustrates the mean biceps brachii MEP recruitment curves in control (blue) and SCI (orange) groups. The $x$ axis of the graph shows the intensity of TMS and the $y$ axis shows the MEP size normalized to the M-max. Control and SCI groups showed similar MEP-max and slope. In biceps brachii, no difference was found for the MEP-max between control (47.0 $\pm 24.3 \%$ of the M-max) and SCI $(45.4 \pm 25.7 \%$ of the M-max, $U=134.0$, $p=0.9, r=0.007)$ groups. There was also no difference found for the slope of the MEP recruitment curve between control $(1.3 \pm 0.9)$ and SCI $(1.3 \pm 0.9, U=126.0, p=0.8, r=0.06)$ groups. Since MEPs were normalized to the M-max, we compared these responses across groups. Differences were found for the M-max of the biceps brachii between control $(17.7 \pm 6.2 \mathrm{mV})$ and SCI (13.4 $\pm 5.5 \mathrm{mV}, U=77.0, p=0.04, r=0.4)$ groups. No difference was found in the MEP-max and the slope between control $(\mathrm{MEP}-\max =8.6 \pm 5.5 \mathrm{mV}$; slope $=0.2 \pm 0.2)$ and SCI (MEP$\max =7.2 \pm 5.9 \mathrm{mV}, U=109.0, p=0.4, r=0.2$; slope $=0.2 \pm 0.3$, $U=115.0, p=0.5, r=0.1)$ groups, suggesting that normalization procedures did not influence our results. The latency of the MEPmax was delayed in SCI $(12.3 \pm 1.6 \mathrm{~ms})$ compared with controls $\left(11.3 \pm 0.7 \mathrm{~ms}, t_{(31)}=2.3, p=0.03, d=0.8\right)$, consistent with the view that corticospinal drive is impaired in SCI individuals (Thomas et al., 1997b; Calancie et al., 1999; Perez, 2012). No difference was found in the AMT between control $(41.5 \pm 8.6 \%$ of the MSO) and SCI $\left(45.6 \pm 5.6 \%\right.$ of the MSO, $t_{(31)}=1.6, p=0.1$, $d=0.5$ ) groups. Within the SCI group, no difference was found for the MEP-max $\left(t_{(16)}=0.9, p=0.4, d=0.4\right)$, the slope $\left(t_{(16)}=1.2\right.$, $p=0.2, d=0.6)$, and the M-max $\left(t_{(16)}=1.3, p=0.2, d=0.6\right)$ between participants taking and not taking antispastic medications.

Figure $3 B$ illustrates the mean triceps MEP recruitment curves in control (blue) and SCI (orange) groups. The $x$ axis of the graph shows the intensity of TMS and the $y$ axis shows the MEP size normalized to the M-max. The SCI group showed 

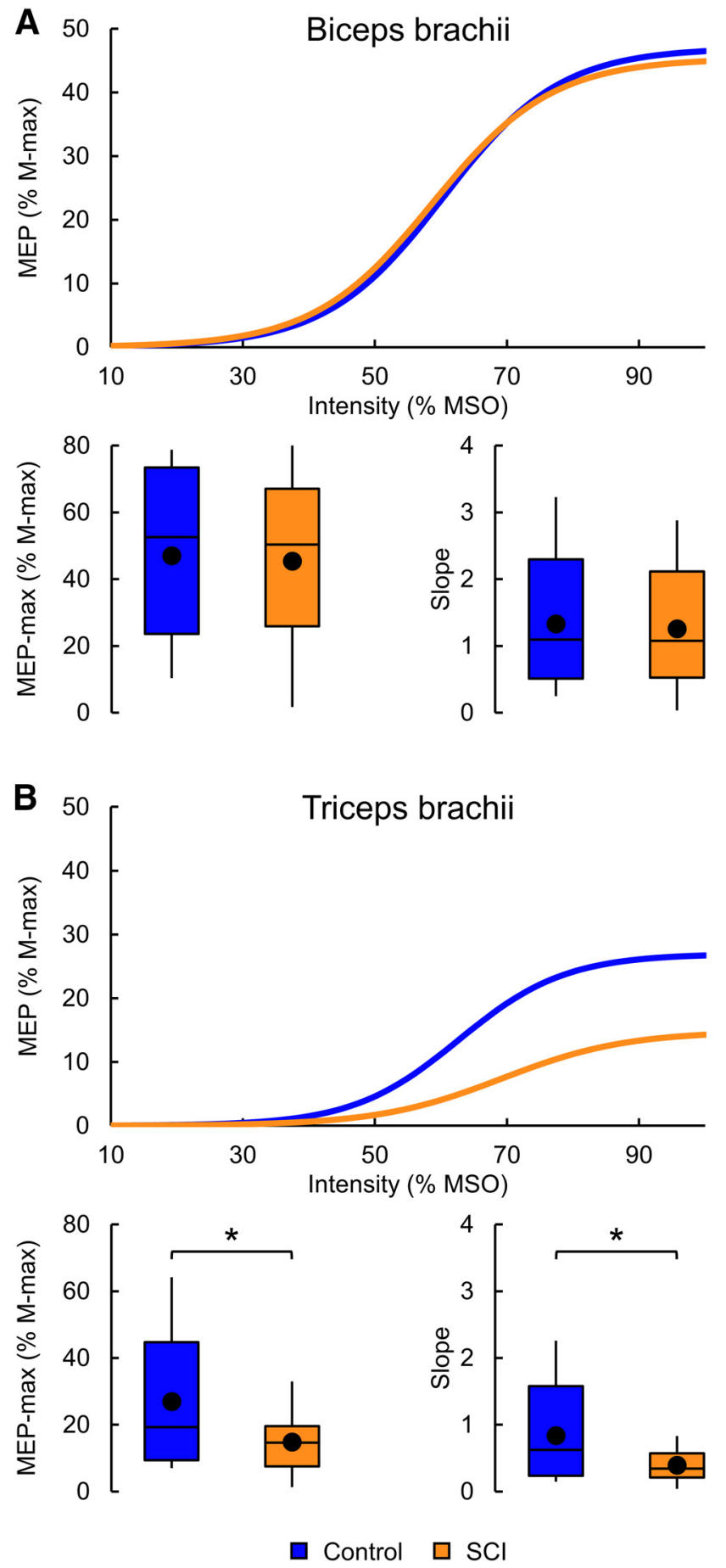

Figure 3. MEP recruitment curves. Mean MEP recruitment curves in biceps $(\boldsymbol{A})$ and triceps $(B)$ brachii of control (blue) and $\mathrm{SCl}$ (orange) groups. The $x$ axis indicates the intensity of TMS and the $y$ axis indicates the MEP size normalized to the M-max. In biceps, the SCl group showed similar MEP-max and slope compare with the control group while in triceps, the SCI group showed reduced MEP-max and slope compare with the control group. Box plot charts represent the group data. Abscissa indicates the groups tested (blue bars represent the control group; orange bars represent the $\mathrm{SCl}$ group). Ordinate indicates the MEP-max as a percentage of the M-max (left) and the slope (right). Top and bottom lines of the box indicate the 75th percentile (top quartile) and 25th percentile (bottom quartile), respectively. Line in the box indicates the 50th percentile (median). The two bars extend from the maximum and minimum value. Dot within the box indicates the arithmetical mean. ${ }^{*} p<0.05$. reduced MEP-max and slope compared with controls. In triceps, we found that the MEP-max was reduced in SCI $(14.8 \pm 8.7 \%$ of the M-max) compared with controls $(27.0 \pm 20.9 \%$ of the M-max, $\left.t_{(31)}=2.3, p=0.03, d=0.8\right)$. The slope of the recruitment curve was also found reduced in SCI $(0.4 \pm 0.2)$ compared with controls $\left(0.8 \pm 0.7, t_{(31)}=2.5, p=0.02, d=0.8\right)$. Since MEPs were normalized to the M-max, we compared these responses across groups. We found that the M-max of the triceps brachii was reduced in SCI $(4.9 \pm 2.6 \mathrm{mV})$ compared with controls $(10.6 \pm 4.4 \mathrm{mV}, U=32.5, p<0.001, r=0.6)$. We also found that the MEP-max and the slope were reduced in SCI (MEP-max $=0.8 \pm 0.6 \mathrm{mV}$; slope $=0.02 \pm 0.02)$ compared with controls (MEP-max $=3.0 \pm 3.1 \mathrm{mV}, \mathrm{U}=27.0, p<0.001, r=0.7$; slope $=0.08 \pm 0.07, U=35.0, p<0.001, r=0.6$ ), suggesting that the normalization procedures did not influence our results. We found that the latency of the MEP-max was delayed in SCI $(14.4 \pm 2.9 \mathrm{~ms})$ compared with controls $(11.3 \pm 1.1 \mathrm{~ms}, U=36.5$, $p<0.001, r=0.6$ ), consistent with the view that corticospinal drive is impaired in SCI individuals. We found that the AMT was increased in SCI $(56.0 \pm 10.3 \%$ of the MSO) compared with controls $\left(47.9 \pm 9.9 \%\right.$ of the MSO, $\left.t_{(31)}=2.3, p=0.03, d=0.8\right)$. Within the SCI group, no difference was found for the MEP$\max \left(t_{(16)}=1.6, p=0.1, d=0.7\right)$, the slope $\left(t_{(16)}=1.5, p=0.2\right.$, $d=1.0)$, and the M-max $\left(t_{(16)}=1.5, p=0.2, d=0.7\right)$ between participants taking and not taking antispastic medications.

Because triceps was weaker than biceps in both groups, in an additional control experiment, we asked all control and SCI participants to adjust their contraction to match biceps and triceps EMG levels during the acquisition of the MEP recruitment curves (controls: biceps $=0.03 \pm 0.02 \mathrm{mV}$, triceps $=0.03 \pm 0.02 \mathrm{mV}, U=108.0, p=0.9, r=0.03 ; n=15$; SCI: biceps $=0.01 \pm 0.01 \mathrm{mV}$, triceps $=0.01 \pm 0.01 \mathrm{mV}, U=$ $150.0, p=0.7, r=0.06 ; n=18)$. In the control group, we found no differences for the MEP-max and the slope between biceps (MEP-max $=34.6 \pm 23.7 \%$ of the M-max; slope $=0.7 \pm 0.6)$ and triceps (MEP- $\max =26.8 \pm 20.6 \%$ of the M-max, $U=87.0, p=0.3, r=0.2$; slope $=0.8 \pm 0.7, U=$ $111.0, p=0.9, r=0.01)$. In the SCI group, we found a reduction of the MEP-max and the slope in triceps (MEP-max $=$ $14.6 \pm 8.6 \%$ of the M-max; slope $=0.4 \pm 0.2$ ) compared with biceps (MEP-max $=31.6 \pm 24.0 \%$ of the M-max, $U=94.0$, $p=0.03, r=0.4$; slope $=0.8 \pm 0.6, U=95.0, p=0.03, r=0.4)$. This information confirms that triceps was more affected than biceps in the SCI group. Because triceps was weaker in SCI than in control participants, in a second additional experiment, we asked 12 SCI and 12 control participants to match their triceps EMG level during the acquisition of the $\mathrm{MEP}$ recruitment curves (controls $=0.03 \pm 0.02 \mathrm{mV}$; SCI $0.02 \pm 0.02 \mathrm{mV}, U=41.0, p=0.1, r=0.4)$. We found that the MEP-max and the slope of the recruitment curve were larger in controls (MEP- $\max =31.8 \pm 20.8 \%$ of the M-max; slope $=1.0 \pm 0.7)$ compared with SCI participants (MEP$\max =13.9 \pm 9.1 \%$ of the $M-\max , U=32.0, p=0.02, r=0.5$; slope $=0.4 \pm 0.3, U=31.0, p=0.02, r=0.5)$. This also confirms our previous results showing that triceps is more affected in SCI compared with controls, supporting the view that the level of voluntary contraction does not affect the MEP-max value (Devanne et al., 1997).

\section{StartReact response}

Figure $4 A$ illustrates the mean EMG activity related to the VRT (black), VART (gray), and VSRT (red) in the biceps and triceps 
of a control subject and a SCI participant. Reaction times in the biceps brachii were similar between control and SCI participants and that reaction times in the triceps were prolonged in all conditions in the SCI compared with the control participant. Notably, in biceps, the shortening in reaction time with a SAS was similar between control and SCI participants but smaller with an acoustic stimulus in SCI participant. In triceps, the shortening of reaction time with an SAS and an acoustic stimulus was similar between control and SCI participants. Repeatedmeasures ANOVA showed no effect of group $\left(F_{(1,31)}=1.8, p=0.2\right)$ but an effect of condition $\left(F_{(2,62)}=273.9, p<0.001\right)$ and in their interaction $\left(F_{(2,62)}=3.6, p=0.03\right)$ on biceps brachii reaction times. Post hoc tests showed that VRT and VSRT were not different between control (VRT: $185.0 \pm 24.1 \mathrm{~ms}$; VSRT: $117.7 \pm 24.0 \mathrm{~ms})$ and SCI groups (VRT: $196.0 \pm 39.5 \mathrm{~ms}, t_{(31)}=0.7$, $p=0.5, d=0.3$; VSRT: $126.8 \pm 33.8 \mathrm{~ms}, t_{(31)}=1.0$, $p=0.3, d=0.3)$. Post hoc tests also showed that VART was prolonged in SCI $(163.8 \pm 40.8 \mathrm{~ms})$ compared with controls $\left(140.3 \pm 26.9 \mathrm{~ms}, t_{(31)}=\right.$ 2.1 $, \quad p=0.04, \quad d=0.7)$. Repeated-measures ANOVA showed an effect of group $\left(F_{(1,31)}=7.8\right.$, $p=0.009)$ and condition $\left(F_{(2,62)}=211.6\right.$, $p<0.001)$ but not in their interaction $\left(F_{(2,62)}=\right.$ $0.1, p=0.9)$ on triceps reaction times. Post hoc tests showed that VRT, VSRT, and VART were prolonged in SCI (VRT: $253.1 \pm 61.7 \mathrm{~ms}$; VSRT: $167.8 \pm 59.1 \mathrm{~ms}$; VART: $194.1 \pm 64.4 \mathrm{~ms})$ compared with controls (VRT: $198.2 \pm 28.7 \mathrm{~ms}, t_{(31)}$ $=2.7, p=0.01, d=1.1$; VSRT: $127.0 \pm 21.7 \mathrm{~ms}$, $t_{(31)}=2.8, \quad p=0.008, \quad d=0.9 ; \quad$ VART: $\left.151.1 \pm 22.1 \mathrm{~ms}, t_{(31)}=2.5, p=0.02, d=0.9\right)$.

Repeated-measures ANOVA showed no effect of group $\left(F_{(1,31)}=0.1, p=0.7\right)$, condition $\left(F_{(2,62)}=0.7, p=0.5\right)$, nor in their interaction $\left(F_{(2,62)}=0.1, p=0.9\right)$ on the mean rectified EMG activity in the biceps muscle measured $100 \mathrm{~ms}$ before stimulus presentation. Similarly, repeated-measures ANOVA showed no effect of group $\left(F_{(1,31)}=0.6, p=0.5\right)$, condition $\left(F_{(2,62)}=0.04, p=1.0\right)$, nor in their interaction $\left(F_{(2,62)}=0.4, p=0.7\right)$ on the mean rectified EMG activity in the triceps muscle measured $100 \mathrm{~ms}$ before stimulus presentation. Repeatedmeasures ANOVA showed no effect of group $\left(F_{(1,31)}=0.01, p=0.9\right)$, but an effect of condition $\left(F_{(2,62)}=50.1, p<0.001\right)$ and in their interaction $\left(F_{(2,62)}=4.7, p=0.01\right)$ on the mean rectified EMG activity in the biceps measured over $100 \mathrm{~ms}$ after the EMG burst onset. Here in both groups, the mean EMG activity was larger during VSRT (control: $0.30 \pm 0.15 \mathrm{mV}$; SCI: $0.25 \pm 0.27 \mathrm{mV}$ ) compared with VRT (control: $0.16 \pm 0.08 \mathrm{mV}$, $t_{(14)}=13.0, p<0.001, \mathrm{dz}=2.9$; SCI: $0.16 \pm 0.20 \mathrm{mV}, t_{(17)}=7.0$, $p<0.001, \mathrm{dz}=0.9)$. Also, the mean EMG activity was larger during VSRT compared with VART (control: $0.19 \pm 0.10 \mathrm{mV}, t_{(14)}=$ 9.8, $p<0.001, \mathrm{dz}=2.9$; SCI: $0.21 \pm 0.26 \mathrm{mV}, t_{(17)}=4.0$, $p<0.001, \mathrm{dz}=1.0)$. The mean EMG activity was larger during VART compared with VRT in the control $\left(t_{(14)}=3.2, p=0.004\right.$, $\mathrm{dz}=1.4)$ and SCI groups $\left(t_{(17)}=3.0, p=0.005, \mathrm{dz}=1.6\right)$. Similarly,

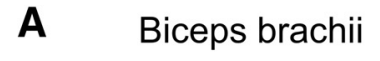

Triceps brachii
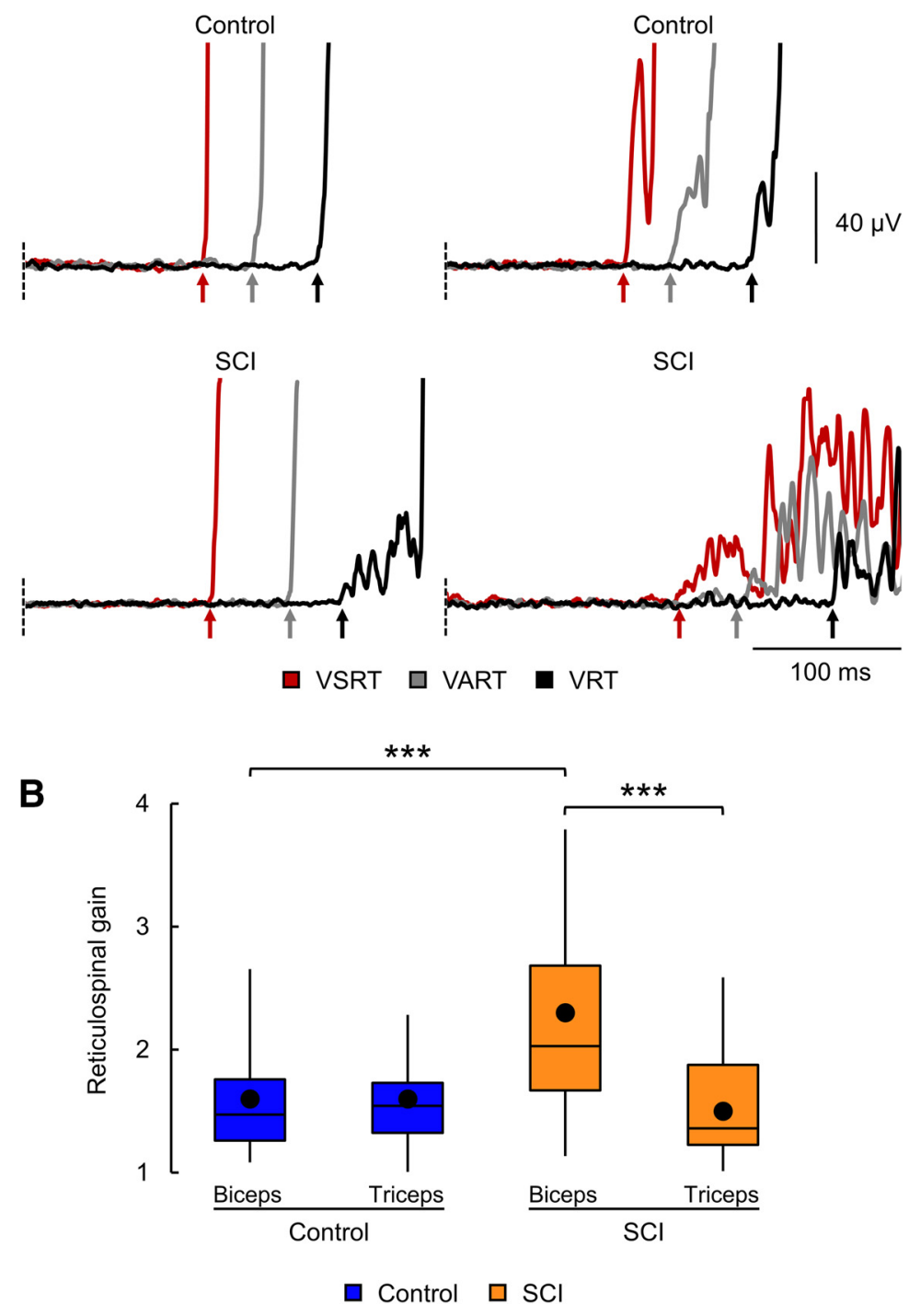

Figure 4. StartReact. $A$, Mean EMG activity related to the VRT (black), VART (gray), and VSRT (red) in the biceps and triceps brachii of a control subject and a participant with SCl. Reaction time was measured as the time from cue (dashed line) to onset of the EMG burst (arrows). Reaction times in biceps brachii were similar between control and $\mathrm{SCl}$ participants, and reaction times in triceps brachii were prolonged in all conditions in the SCI participant compared with control. Notably, in biceps brachii, the shortening of reaction time was similar between control and SCl participants for $\triangle$ TSR but smaller in SCl participant for $\triangle T A R$. In triceps brachii, the shortening of reaction time for $\triangle T S R$ and $\triangle \mathrm{TAR}$ was similar between control and SCl participants. $\boldsymbol{B}$, Box plot charts represent the group data. Abscissa indicates the groups tested (blue bars represent the control group; orange bars represent the SCI group). Ordinate indicates the reticulospinal gain. Top and bottom lines of the box indicate the 75th percentile (top quartile) and 25th percentile (bottom quartile), respectively. Line in the box indicates the 50th percentile (median). The two bars extend from the maximum and minimum value. Dot within the box indicates the arithmetical mean. ${ }^{* * *} p<0.001$.

repeated-measures ANOVA showed an effect of group $\left(F_{(1,31)}=\right.$ $5.0, p=0.03)$, condition $\left(F_{(2,62)}=18.4, p<0.001\right)$, and in their interaction $\left(F_{(2,62)}=7.0, p=0.002\right)$ on the mean rectified EMG activity in the triceps measured over $100 \mathrm{~ms}$ after the EMG burst onset. Here in both groups, the mean EMG activity was larger during VSRT (control: $0.17 \pm 0.14 \mathrm{mV}$; SCI: $0.07 \pm 0.10 \mathrm{mV}$ ) compared with VRT (control: $0.08 \pm 0.05 \mathrm{mV}, t_{(14)}=9.2$, $p<0.001, \mathrm{dz}=1.5$; SCI: $0.04 \pm 0.06 \mathrm{mV}, t_{(17)}=11.8, p<0.001$, $\mathrm{dz}=2.5)$. Also, the mean EMG activity was larger during VSRT compared with VART (control: $0.10 \pm 0.07 \mathrm{mV}, t_{(14)}=$ 6.8, $p<0.001, \mathrm{dz}=2.9$; SCI: $0.05 \pm 0.07 \mathrm{mV}, t_{(17)}=6.9$, $p<0.001, \mathrm{dz}=3.1)$. The mean EMG activity was larger during 
VART compared with VRT in control $\left(t_{(14)}=2.4, p=0.02\right.$, $\mathrm{dz}=2.0)$ and SCI groups $\left(t_{(17)}=4.9, p<0.001, \mathrm{dz}=2.6\right)$.

To ensure that any changes in reaction times were related to changes in reticulospinal gain, we compared the $\Delta T S R / \Delta T A R$ ratios across groups. Two-way ANOVA showed an effect of group $\left(F_{(1,62)}=6.2, p=0.02\right)$ and muscle $\left(F_{(1,62)}=7.5, p=0.008\right)$ and in their interaction $\left(F_{(1,62)}=7.4, p=0.008\right)$ on the $\Delta \mathrm{TSR} /$ $\triangle$ TAR ratios (Fig. $4 B$ ). Post hoc tests showed that the reticulospinal gain was not different between biceps $(1.6 \pm 0.4)$ and triceps in the control group $\left(1.6 \pm 0.3, t_{(28)}=0.004, p=1.0, d=0.0\right)$ but was larger in biceps $(2.3 \pm 0.8)$ compared with triceps in the SCI group $\left(1.5 \pm 0.5, t_{(34)}=4.0, p<0.001, d=1.2\right)$. Post hoc tests also showed that the reticulospinal gain in biceps was larger in SCI compared with controls $\left(t_{(31)}=3.7, p<0.001, d=1.1\right)$, while no difference was found in triceps between groups $\left(t_{(31)}=0.2\right.$, $p=0.9, d=0.2)$. Within the SCI group, the reticulospinal gain remained similar between participants taking and not taking antispastic medication (biceps, $t_{(16)}=0.9, p=0.4, d=0.4$; triceps, $\left.t_{(16)}=1.7, p=0.3, d=0.5\right)$.

\section{CMEPs}

Figure $5 \mathrm{~A}$ illustrates the mean CMEP-test in a control subject and a participant with SCI (CMEP-test, black) and the facilitation of the CMEP induced by an SAS (CMEP-startle, gray). The SCI participant exhibited a larger facilitation of the CMEP-startle in biceps but a similar facilitation in triceps compared with the control participant. Two-way ANOVA showed no effect of group $\left(F_{(1,44)}=0.2, p=0.6\right)$, muscle $\left(F_{(1,44)}=3.5, p=0.1\right)$, nor in their interaction $\left(F_{(1,44)}=0.7, p=0.4\right)$ on the amplitude of the CMEPtest (controls: biceps $=1.3 \pm 0.6 \mathrm{mV}$ and triceps: $0.9 \pm 0.3 \mathrm{mV}$; SCI: biceps $=1.3 \pm 0.7 \mathrm{mV}$ and triceps $=1.1 \pm 0.6 \mathrm{mV})$. However, two-way ANOVA showed an effect of group $\left(F_{(1,44)}=10.5\right.$, $p=0.002)$, muscle $\left(F_{(1,44)}=13.1, p<0.001\right)$, and in their interaction $\left(F_{(1,44)}=11.7, p=0.001\right)$ on the amplitude of the CMEP-startle (Fig. $5 B)$. Post hoc tests showed that the CMEP-startle expressed as a percentage of the CMEP-test was not different between biceps $(121.5 \pm 8.3 \%$ of the CMEP-test) and triceps $(120.1 \pm 20.0 \%$ of the CMEP-test, $\left.t_{(22)}=0.1, p=0.9, d=0.09\right)$ in the control group, but it was larger in biceps (165.5 $\pm 38.0 \%$ of the CMEP-test) compared with triceps $\left(118.9 \pm 13.6 \%\right.$ of the CMEP-test, $t_{(22)}=5.0, p<0.001$, $d=1.6$ ) in the SCI group. Post hoc tests also showed that the CMEP-startle was larger in SCI compared with controls in biceps $\left.t_{(22)}=4.7, p<0.001, d=1.6\right)$ but not in triceps $\left(t_{(22)}=0.1, p=0.9\right.$, $d=0.07)$. We found that the latency of the CMEP test was delayed in biceps and triceps in SCI (biceps: $9.5 \pm 1.1 \mathrm{~ms}$; triceps: $9.1 \pm$ $1.2 \mathrm{~ms}$ ) compared with controls (biceps: $8.2 \pm 0.8 \mathrm{~ms}, t_{(22)}=3.2, p=$ $0.004, d=1.3$; triceps: $7.6 \pm 1.2 \mathrm{~ms}, t(22)=3.1, p=0.005, d=1.2$ ), consistent with the view that descending motor drive is impaired in SCI individuals. Within the SCI group, no difference was found on the CMEP-startle facilitation in biceps $\left(t_{(10)}=0.1, p=0.9, d=0.06\right)$ and triceps $\left(t_{(10)}=0.5, p=0.6, d=0.3\right)$ between participants taking and not taking antispastic medications.

\section{Correlations}

No correlations were found between any of the physiological outcomes acquired in biceps (MVC, $r=0.1, p=0.7$; MEP-max, $r=0.3, p=0.3$; slope, $r=0.4, p=0.1$; M-max, $r=0.2, p=0.4$; reticulospinal gain, $r=-0.5, p=0.1$ ) and triceps (MVC, $r=0.2$, $p=0.4$; MEP-max, $r=-0.1, p=0.8$; slope, $r=0.01, p=1.0$; Mmax, $r=0.2, p=0.3$; reticulospinal gain, $r=0.2, p=0.5$ ) and the level of injury. Similarly, no correlations were found between physiological outcomes in biceps (MVC, $r=-0.2, p=0.3$; MEP$\max , r=-0.2, p=0.4$; slope, $r=-0.3, p=0.2$; M-max, $r=-0.3$,
A Biceps brachii

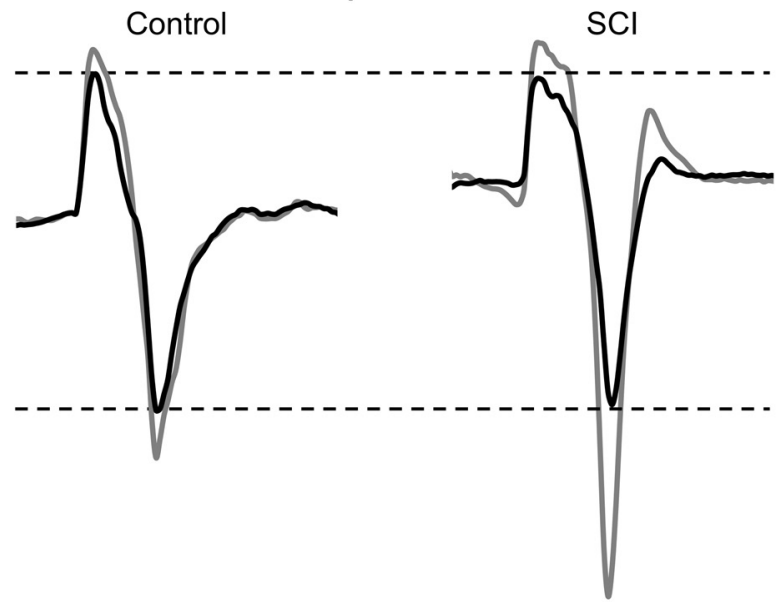

Triceps brachii
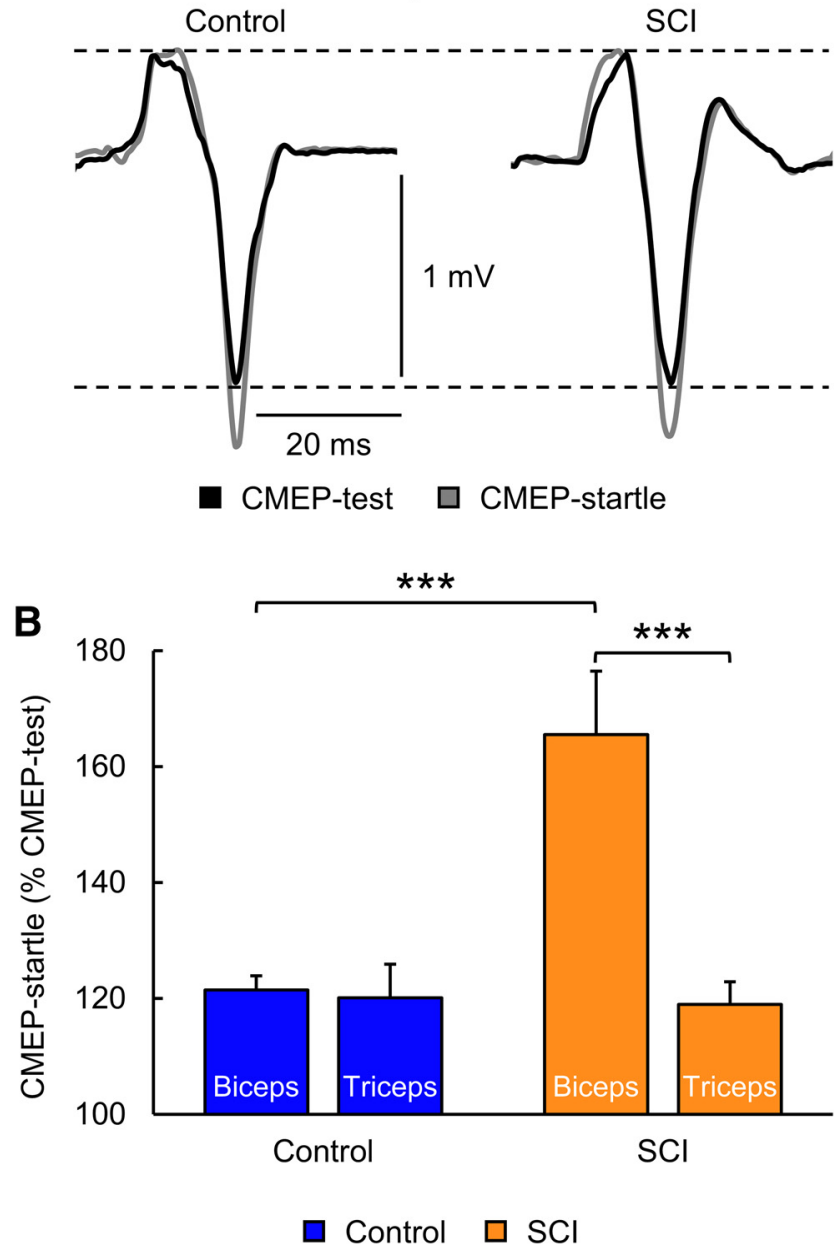

Figure 5. CMEPs. A, Mean CMEP-test (black) and CMEP-startle (gray) elicited in the biceps and triceps brachii of a control subject and a participant with SCI. The SCI participant exhibited a larger facilitation of the CMEP-startle in biceps but to a similar extent in triceps brachii compared with the control subject. B, Graph represents group data. Abscissa indicates the groups tested (blue bars represent the control group; orange bars represent the $\mathrm{SCI}$ group). Ordinate indicates the facilitation of CMEP-startle as a percentage of the CMEP-test. Error bars indicate SEM. ${ }^{* *} p<0.001$.

$p=0.2$; reticulospinal gain, $r=0.2, p=0.4$ ) and triceps (MVC, $r=$ $-0.1, p=0.8$; MEP-max, $r=0.4, p=0.1$; slope, $r=0.4, p=0.2$; Mmax, $r=-0.3, p=0.2$; reticulospinal gain, $r=-0.3, p=0.3)$ and the medication intake and the time after injury (biceps: MVC, 
$r=-0.004, p=1.0 ;$ MEP- $\max , r=0.1, p=0.8$; slope, $r=-0.01$, $p=1.0 ; \mathrm{M}$-max, $r=-0.2, p=0.5$; reticulospinal gain, $r=$ $-0.4, p=0.1$ and triceps: MVC, $r=0.02, p=0.9$; MEP-max, $r=$ $0.1, p=0.7$; slope, $r=0.01, p=1.0$; M-max, $r=0.2, p=0.5$; reticulospinal gain, $r=-0.1, p=0.6)$.

\section{Discussion}

In the present study, we show that corticospinal and reticulospinal pathways contribute to a different extent to the control of biceps and triceps in humans with tetraplegia. On the one hand, we found similar MEPs and MVCs but increased StartReact and CMEP facilitation in the biceps in SCI compared with controls. On the other hand, we found smaller MEPs and MVCs and similar StartReact and CMEP facilitation in the triceps in SCI compared with controls. Collectively, these results suggest that the recovery of biceps after cervical SCI results, at least in part, from increased reticulospinal inputs and that the lack of these extra inputs combined with the loss of corticospinal drive might contribute to the pronounced weakness found in triceps. This knowledge might help the design of therapeutic strategies for upper limb function after SCI.

\section{Descending control of elbow flexor and extensor muscles after SCI}

Our findings support the view that biceps receive strong corticospinal inputs compared with triceps in people with and without SCI. We found that the amplitude of MEPs (Brouwer and Hopkins-Rosseel, 1997) and maximal contractions (Ditunno et al., 1992, 2000; Murray et al., 2000; Calancie et al., 2004; McKay et al., 2011) were larger in biceps compared with triceps in both groups. We also found that MEPs in triceps were reduced in amplitude and had delayed latencies in SCI compared with controls, as previously shown (Thomas et al., 1997b; Calancie et al., 1999; Perez, 2012). MEPs elicited by TMS over the primary motor cortex provide an index of corticospinal excitability (Lemon et al., 1995; Petersen et al., 2003) and that the corticospinal tract plays a major role in the control of voluntary movement (Lemon, 2008) in monkeys (Fetz and Cheney, 1980) and humans (Day et al., 1987, 1989). An intriguing question is why the amplitude of corticospinal responses in SCI participants was similar to controls in biceps but not in triceps. Motor cortical representations of biceps and triceps are in close locations in monkeys (Kwan et al., 1978) and humans (Penfield and Boldrey, 1937). Indeed, there is a large overlap on the corticospinal sites from which elbow flexor and extensor movements can be evoked (Graziano et al., 2004; Graziano, 2006) and on corticospinal neurons controlling elbow flexor and extensor muscles (Witham et al., 2016). The location of motoneurons innervating biceps and triceps also largely overlaps (Schirmer et al., 2011), and most injuries to the cervical spinal cord affect more than one spinal segment (Schaefer et al., 1989; Benavides et al., 2020). Thus, it is unlikely that, following SCI, corticospinal projections and/or motoneurons innervating triceps were more damaged compared with those innervating biceps. It is also unlikely that our results relate to differences in stimulation parameters. As before (Perez et al., 2014), we found similar MEP thresholds for biceps and triceps in controls. This also agrees with our results in SCI participants showing that, although MEP thresholds were higher in triceps than biceps, smaller MEPs were elicited in triceps.

We favor two possible explanations for our results. The first possibility is that the recovery of responses in biceps after SCI involves reticulospinal compensatory mechanisms. This is supported by our results showing that the StartReact and CMEP facilitation were larger in biceps compared with controls. The StartReact likely reflects an involuntary release of a planned movement when an unexpected startle cue is presented (Brown et al., 1991; Valls-Solé et al., 1995, 1999). Although the shortening in reaction time likely involves subcortical structures, such as the reticular formation (Davis and Gendelman, 1977; Valls-Solé et al., 1999; Carlsen et al., 2003, 2004, 2009), a contribution from cortical pathways cannot be excluded (Marinovic and Tresilian, 2016). Indeed, Dean and Baker (2017) showed that StartReact responses in finger muscles showed a similar degree of muscle fractionation during rapid responses without a startling cue, suggesting that reticulospinal and corticospinal pathways contributed in parallel to the StartReact. If this is the case, why did we not observe the same results in triceps? In triceps, we found that the StartReact response was similar between groups. Stimulation of the pontomedullary reticular formation in monkeys results in a series of bilateral reciprocal patterns with a tendency to facilitate ipsilateral flexors and inhibit ipsilateral extensors and to facilitate contralateral extensors and inhibit contralateral flexors (Davidson and Buford, 2006; Davidson et al., 2007; Herbert et al., 2010; Hirschauer and Buford, 2015). Because reticulospinal axons are bilaterally distributed with a majority of ipsilateral axons in monkeys and humans (Nathan et al., 1996; Sakai et al., 2009), it might not be surprising that ipsilateral effects are predominant. Indeed, corticospinal lesions in primates lead to enhanced monosynaptic and disynaptic reticulospinal facilitation to forearm flexors compared with extensor muscles (Zaaimi et al., 2012). We therefore hypothesized a preferential facilitatory contribution of reticulospinal inputs to biceps compared with triceps motoneurons after SCI. One possibility is that reticulospinal inputs compensate for the loss of corticospinal axons (Pettersson et al., 2000; Zaaimi et al., 2012). This is supported by our results showing that, when a startle cue was given $80 \mathrm{~ms}$ before a CMEP, an interval reflecting influences from subcortical pathways (Furubayashi et al., 2000; Tazoe and Perez, 2017), the CMEP amplitude increased in biceps but not in triceps. This is also supported by the fact that these changes were observed in SCI but not in controls, underlying the view that these changes might be related to reorganization after the injury.

The second possibility is that our results relate to differences in the nature of the distribution of corticospinal projections to biceps and triceps. The terminal distribution of crossed and ipsilateral corticospinal projections to interneurons and motoneurons is larger in biceps compared with triceps (Morecraft et al., 2013). In addition, in monkeys (Phillips and Porter, 1964; McKiernan et al., 1998) and humans (Palmer and Ashby, 1992; de Noordhout et al., 1999), biceps motoneurons receive large corticospinal monosynaptic facilitation, whereas triceps motoneurons receive lesser monosynaptic facilitation but strong disynaptic inhibition. Thus, it is possible that responses in biceps in SCI participants reflect the large direct facilitatory corticospinal control. A larger facilitatory effect on biceps can contribute to the increases observed in reticulospinal gain. This agrees with evidence showing that increases in corticospinal excitability can result in shorter reaction time (Benito et al., 2012; Bunday and Perez, 2012; Long et al., 2017). This is also supported by our data showing larger MEP responses in biceps compared with triceps in SCI participants. Overall, our results support the possibility that both processes, either reticulospinal inputs compensate for the loss of corticospinal axon and/or that large direct facilitatory corticospinal control contributed to the results observed in biceps. It is of interest to note that the properties of motoneurons for both muscles differ. Persistent inward currents, which 
amplify synaptic input and promote self-sustained firing, are higher in the lateral head of the triceps than in the biceps brachii during isometric contractions (Wilson et al., 2015). This is consistent with evidence showing a higher incidence for persistent inward currents in extensor compared with flexor muscles (Hounsgaard et al., 1988; Cotel et al., 2009). Although the loss of descending drive to motoneurons leads to enhanced persistent inward currents (Gorassini et al., 2004), the similar effects of a startling cue in our measurements in the elbow extensor muscle between SCI and control suggest that it is less likely that differences in amplification of synaptic input at the motoneuronal level contributed to our findings.

\section{Functional considerations}

Multiple descending motor pathways likely contribute to the recovery of function after SCI. A critical question is how these contributions might take place. For example, we recently showed lesser corticospinal and larger reticulospinal influences to spastic muscles in humans with SCI (Sangari and Perez, 2019), suggesting that the contributions from corticospinal and reticulospinal tracts are imbalanced when spasticity is present (Owen et al., 2017; McPherson et al., 2018; Choudhury et al., 2019). Here, we tested SCI participants who did not have spasticity in biceps or triceps to avoid the effect of this variable on our results. Spasticity is also present to a much lesser extent in upper compared with lower limb muscles (Sköld et al., 1999). Interestingly, we found increased reticulospinal inputs to biceps and decreased corticospinal inputs to triceps. Is this good or bad reorganization? Discussions are still ongoing about the positive or negative nature of reticulospinal reorganization after CNS damage (Brunnstrom, 1970; Karbasforoushan et al., 2019). Our present and previous results (Baker and Perez, 2017) favor the interpretation that reticulospinal reorganization can contribute to functional tasks. This is consistent with evidence in animal models of SCI showing that injured reticulospinal axons form new connections that can contribute to functional recovery (Wakabayashi et al., 2001; Ballermann and Fouad, 2006; Filli et al., 2014; May et al., 2017). Others have also suggested that the recovery of strength in patients with CNS damage involves strengthening of the reticulospinal pathway (Xu et al., 2017; Choudhury et al., 2019). Therapeutically, increased engagement of both corticospinal and reticulospinal inputs might then help the recovery of triceps after SCI; and if spasticity is present, favoring corticospinal inputs might be a preferred approach (Sangari and Perez, 2019). Whether reorganization in reticulospinal pathways is "good" or "bad" might depend on a number of factors, and this might also differ across patient populations, across control of upper and lower limb muscles, and even across muscles of the upper limb as shown in the present study.

\section{References}

Asboth L, Friedli L, Beauparlant J, Martinez-Gonzalez C, Anil S, Rey E, Baud L, Pidpruzhnykova G, Anderson MA, Shkorbatova P, Batti L, Pagès S, Kreider J, Schneider BL, Barraud Q, Courtine G (2018) Cortico-reticulospinal circuit reorganization enables functional recovery after severe spinal cord contusion. Nat Neurosci 21:576-588.

Baker SN, Perez MA (2017) Reticulospinal contributions to gross hand function after human spinal cord injury. J Neurosci 37:9778-9784.

Ballermann M, Fouad K (2006) Spontaneous locomotor recovery in spinal cord injured rats is accompanied by anatomical plasticity of reticulospinal fibers. Eur J Neurosci 23:1988-1996.

Benavides FD, Jo HJ, Lundell H, Edgerton VR, Gerasimenko Y, Perez MA (2020) Cortical and subcortical effects of transcutaneous spinal cord stimulation in humans with tetraplegia. J Neurosci 40:2633-2643.
Benito J, Kumru H, Murillo N, Costa U, Medina J, Tormos J, Pascual-Leone A, Vidal J (2012) Motor and gait improvement in patients with incomplete spinal cord injury induced by high-frequency repetitive transcranial magnetic stimulation. Top Spinal Cord Inj Rehabil 18:106-112.

Brouwer B, Hopkins-Rosseel DH (1997) Motor cortical mapping of proximal upper extremity muscles following spinal cord injury. Spinal Cord 35:205-212.

Brown P, Rothwell JC, Thompson PD, Britton TC, Day BL, Marsden CD (1991) New observations on the normal auditory startle reflex in man. Brain 114:1891-1902.

Brunnstrom S (1970) Movement therapy in hemiplegia: a neurophysiological approach. New York: Harper and Row.

Bunday KL, Perez MA (2012) Motor recovery after spinal cord injury enhanced by strengthening corticospinal synaptic transmission. Curr Biol 22:2355-2361.

Calancie B, Alexeeva N, Broton JG, Suys S, Hall A, Klose KJ (1999) Distribution and latency of muscle responses to transcranial magnetic stimulation of motor cortex after spinal cord injury in humans. J Neurotrauma 16:49-67.

Calancie B, Molano MR, Broton JG (2004) EMG for assessing the recovery of voluntary movement after acute spinal cord injury in man. Clin Neurophysiol 115:1748-1759.

Carlsen AN, Hunt MA, Inglis JT, Sanderson DJ, Chua R (2003) Altered triggering of a prepared movement by a startling stimulus. J Neurophysiol 89:1857-1863.

Carlsen AN, Chua R, Inglis JT, Sanderson DJ, Franks IM (2004) Can prepared responses be stored subcortically? Exp Brain Res 159:301-309.

Carlsen AN, Chua R, Inglis JT, Sanderson DJ, Franks IM (2009) Differential effects of startle on reaction time for finger and arm movements. J Neurophysiol 101:306-314.

Carroll TJ, Riek S, Carson RG (2001) Reliability of the input-output properties of the cortico-spinal pathway obtained from transcranial magnetic and electrical stimulation. J Neurosci Methods 112:193-202.

Choudhury S, Shobhana A, Singh R, Sen D, Anand SS, Shubham S, Baker MR, Kumar H, Baker SN (2019) The relationship between enhanced reticulospinal outflow and upper limb function in chronic stroke patients. Neurorehabil Neural Repair 33:375-383.

Cotel F, Antri M, Barthe JY, Orsal D (2009) Identified ankle extensor and flexor motoneurons display different firing profiles in the neonatal rat. J Neurosci 29:2748-2753.

Davidson AG, Buford JA (2006) Bilateral actions of the reticulospinal tract on arm and shoulder muscles in the monkey: stimulus triggered averaging. Exp Brain Res 173:25-39.

Davidson AG, Schieber MH, Buford JA (2007) Bilateral spike-triggered average effects in arm and shoulder muscles from the monkey pontomedullary reticular formation. J Neurosci 27:8053-8058.

Davis M, Gendelman PM (1977) Plasticity of the acoustic startle response in the acutely decerebrate rat. J Comp Physiol Psychol 91:549-563.

Davis M, Gendelman DS, Tischler MD, Gendelman PM (1982) A primary acoustic startle circuit: lesion and stimulation studies. J Neurosci 2:791805.

Day BL, Rothwell JC, Thompson PD, Dick JP, Cowan JM, Berardelli A, Marsden CD (1987) Motor cortex stimulation in intact man: 2. Multiple descending volleys. Brain 110:1191-1209.

Day BL, Dressler D, Maertens de Noordhout A, Marsden CD, Nakashima K, Rothwell JC, Thompson PD (1989) Electric and magnetic stimulation of human motor cortex: surface EMG and single motor unit responses. J Physiol 412:449-473.

de Noordhout AM, Rapisarda G, Bogacz D, Gérard P, De Pasqua V, Pennisi G, Delwaide PJ (1999) Corticomotoneuronal synaptic connections in normal man. Brain 122:1327-1340.

Dean LR, Baker SN (2017) Fractionation of muscle activity in rapid responses to startling cues. J Neurophysiol 117:1713-1719.

Devanne H, Lavoie BA, Capaday C (1997) Input-output properties and gain changes in the human corticospinal pathway. Exp Brain Res 114:329338.

Ditunno JF, Stover SL, Freed MM, Ahn JH (1992) Motor recovery of the upper extremities in traumatic quadriplegia: a multicenter study. Arch Phys Med Rehabil 73:431-436.

Ditunno JF, Cohen ME, Hauck WW, Jackson AB, Sipski ML (2000) Recovery of upper-extremity strength in complete and incomplete tetraplegia: a multicenter study. Arch Phys Med Rehabil 81:389-393. 
Fetz EE, Cheney PD (1980) Postspike facilitation of forelimb muscle activity by primate corticomotoneuronal cells. J Neurophysiol 44:751-772.

Filli L, Engmann AK, Zorner B, Weinmann O, Moraitis T, Gullo M, Kasper H, Schneider R, Schwab ME (2014) Bridging the gap: a reticulo-propriospinal detour bypassing an incomplete spinal cord injury. J Neurosci 34:13399-13410.

Fisher KM, Chinnery PF, Baker SN, Baker MR (2013) Enhanced reticulospinal output in patients with (REEP1) hereditary spastic paraplegia type 31 . J Neurol 260:3182-3184.

Furubayashi T, Ugawa Y, Terao Y, Hanajima R, Sakai K, Machii K, Mochizuki H, Shiio Y, Uesugi H, Enomoto H, Kanazawa I (2000) The human hand motor area is transiently suppressed by an unexpected auditory stimulus. Clin Neurophysiol 111:178-183.

Gorassini MA, Knash ME, Harvey PJ, Bennett DJ, Yang JF (2004) Role of motoneurons in the generation of muscle spasms after spinal cord injury. Brain 127:2247-2258.

Graziano M (2006) The organization of behavioral repertoire in motor cortex. Annu Rev Neurosci 29:105-134.

Graziano MS, Patel KT, Taylor CSR (2004) Mapping from motor cortex to biceps and triceps altered by elbow angle. J Neurophysiol 92:395-407.

Grumbles RM, Thomas CK (2017) Motoneuron death after human spinal cord injury. J Neurotrauma 34:581-590.

Herbert WJ, Davidson AG, Buford JA (2010) Measuring the motor output of the pontomedullary reticular formation in the monkey: do stimulus-triggered averaging and stimulus trains produce comparable results in the upper limbs? Exp Brain Res 203:271-283.

Hirschauer TJ, Buford JA (2015) Bilateral force transients in the upper limbs evoked by single-pulse microstimulation in the pontomedullary reticular formation. J Neurophysiol 113:2592-2604.

Hounsgaard J, Hultborn H, Jespersen B, Kiehn O (1988) Bistability of alphamotoneurones in the decerebrate cat and in the acute spinal cat after intravenous 5-hydroxytryptophan. J Physiol 405:345-367.

Ilic TV, Pötter-Nerger M, Holler I, Siebner HR, Ilic NV, Deuschl G, Volkmann J (2011) Startle stimuli exert opposite effects on human cortical and spinal motor system excitability in leg muscles. Physiol Res 60: S101.

Johanson M, Lateva Z, Jaramillo J, Kiratli B, McGill K (2013) Triceps brachii in incomplete tetraplegia: EMG and dynamometer evaluation of residual motor resources and capacity for strengthening. Top Spinal Cord Inj Rehabil 19:300-310.

Karbasforoushan H, Cohen-Adad J, Dewald JPA (2019) Brainstem and spinal cord MRI identifies altered sensorimotor pathways post-stroke. Nat Commun 10:3524.

Kühn AA, Sharott A, Trottenberg T, Kupsch A, Brown P (2004) Motor cortex inhibition induced by acoustic stimulation. Exp Brain Res 158:120124.

Kwan HC, MacKay WA, Murphy JT, Wong YC (1978) Spatial organization of precentral cortex in awake primates: II. Motor outputs. J Neurophysiol $41: 1120-1131$

Lemon RN (2008) Descending pathways in motor control. Annu Rev Neurosci 31:195-218.

Lemon RN, Johansson RS, Westling G (1995) Corticospinal control during reach, grasp, and precision lift in man. J Neurosci 15:6145-6156.

Long J, Federico P, Perez MA (2017) A novel cortical target to enhance hand motor output in humans with spinal cord injury. Brain 140:1619-1632.

Marinovic W, Tresilian JR (2016) Triggering prepared actions by sudden sounds: reassessing the evidence for a single mechanism. Acta Physiol (Oxf) 217:13-32.

May Z, Fenrich KK, Dahlby J, Batty NJ, Torres-Espín A, Fouad K (2017) Following spinal cord injury transected reticulospinal tract axons develop new collateral inputs to spinal interneurons in parallel with locomotor recovery. Neural Plasticity 2017:1-15.

McKay WB, Ovechkin AV, Vitaz TW, Terson de Paleville DG, Harkema SJ (2011) Neurophysiological characterization of motor recovery in acute spinal cord injury. Spinal Cord 49:421-429.

McKiernan BJ, Marcario JK, Karrer JH, Cheney PD (1998) Corticomotoneuronal postspike effects in shoulder, elbow, wrist, digit, and intrinsic hand muscles during a reach and prehension task. J Neurophysiol 80:1961-1980.

McPherson JG, Chen A, Ellis MD, Yao J, Heckman CJ, Dewald JP (2018) Progressive recruitment of contralesional cortico-reticulospinal pathways drives motor impairment post stroke. J Physiol 596:1211-1225.
Morecraft RJ, Ge J, Stilwell-Morecraft KS, McNeal DW, Pizzimenti MA, Darling WG (2013) Terminal distribution of the corticospinal projection from the hand/arm region of the primary motor cortex to the cervical enlargement in rhesus monkey: precentral corticospinal projection in monkey. J Comp Neurol 521:4205-4235.

Murray WM, Buchanan TS, Delp SL (2000) The isometric functional capacity of muscles that cross the elbow. J Biomech 33:943-952.

Nathan PW, Smith M, Deacon P (1996) Vestibulospinal, reticulospinal and descending propriospinal nerve fibres in man. Brain 119:1809-1833.

Oudega M, Perez MA (2012) Corticospinal reorganization after spinal cord injury: corticospinal tract and SCI. J Physiol 590:3647-3663.

Owen M, Ingo C, Dewald JPA (2017) Upper extremity motor impairments and microstructural changes in bulbospinal pathways in chronic hemiparetic stroke. Front Neurol 8:257.

Palmer E, Ashby P (1992) Corticospinal projections to upper limb motoneurones in humans. J Physiol 448:397-412.

Penfield W, Boldrey E (1937) Somatic motor and sensory representation in the cerebral cortex of man as studied by electrical stimulation. Brain 60:389-443.

Perez MA (2012) Transcranial magnetic stimulation and spinal cord injury. In: Cortical connectivity: brain stimulation for assessing and modulating cortical connectivity and function (Chen R, Rothwell JC, eds), pp 323336. Berlin: Springer.

Perez MA, Butler JE, Taylor JL (2014) Modulation of transcallosal inhibition by bilateral activation of agonist and antagonist proximal arm muscles. J Neurophysiol 111:405-414.

Petersen NT, Pyndt HS, Nielsen JB (2003) Investigating human motor control by transcranial magnetic stimulation. Exp Brain Res 152:1-16.

Pettersson LG, Blagovechtchenski E, Perfiliev S, Krasnochokova E, Lundberg A (2000) Recovery of food-taking in cats after lesions of the corticospinal (complete) and rubrospinal (complete and incomplete) tracts. Neurosci Res 38:109-112.

Phillips CG, Porter R (1964) The pyramidal projection to motoneurones of some muscle groups of the baboon's forelimb. In: Progress in brain research, pp 222-245. Amsterdam: Elsevier.

Sakai ST, Davidson AG, Buford JA (2009) Reticulospinal neurons in the pontomedullary reticular formation of the monkey (Macaca fascicularis). Neuroscience 163:1158-1170.

Sangari S, Perez MA (2019) Imbalanced corticospinal and reticulospinal contributions to spasticity in humans with spinal cord injury. J Neurosci 39:7872-7881.

Schaefer DM, Flanders A, Northrup BE, Doan HT, Osterholm JL (1989) Magnetic resonance imaging of acute cervical spine trauma: correlation with severity of neurologic injury. Spine 14:1090-1095.

Schirmer CM, Shils JL, Arle JE, Cosgrove GR, Dempsey PK, Tarlov E, Kim S, Martin CJ, Feltz C, Moul M, Magge S (2011) Heuristic map of myotomal innervation in humans using direct intraoperative nerve root stimulation. J Neurosurg Spine 15:64-70.

Sköld C, Levi R, Seiger A (1999) Spasticity after traumatic spinal cord injury: nature, severity, and location. Arch Phys Med Rehabil 80:1548-1557.

Taylor JL, Gandevia SC (2004) Noninvasive stimulation of the human corticospinal tract. J Appl Physiol 96:1496-1503.

Tazoe T, Perez MA (2017) Cortical and reticular contributions to human precision and power grip: control of precision and power grip. J Physiol 595:2715-2730.

Thomas CK, Broton JG, Calancie B (1997a) Motor unit forces and recruitment patterns after cervical spinal cord injury. Muscle Nerve 20:212-220.

Thomas CK, Zaidner EY, Calancie B, Broton JG, Bigland-Ritchie BR (1997b) Muscle weakness, paralysis, and atrophy after human cervical spinal cord injury. Exp Neurol 148:414-423.

Thomas CK, Tucker ME, Bigland-Ritchie B (1998) Voluntary muscle weakness and co-activation after chronic cervical spinal cord injury. J Neurotrauma 15:149-161

Valls-Solé J, Solé A, Valldeoriola F, Muñoz E, Gonzalez LE, Tolosa ES (1995) Reaction time and acoustic startle in normal human subjects. Neurosci Lett 195:97-100.

Valls-Solé J, Rothwell JC, Goulart F, Cossu G, Muñoz E (1999) Patterned ballistic movements triggered by a startle in healthy humans. J Physiol 516:931-938.

Vavrek R, Pearse DD, Fouad K (2007) Neuronal populations capable of regeneration following a combined treatment in rats with spinal cord transection. J Neurotrauma 24:1667-1673. 
Wakabayashi Y, Komori H, Kawa-Uchi T, Mochida K, Takahashi M, Qi M, Otake K, Shinomiya K (2001) Functional recovery and regeneration of descending tracts in rats after spinal cord transection in infancy. Spine 26:1215-1222.

Wilson JM, Thompson CK, Miller LC, Heckman CJ (2015) Intrinsic excitability of human motoneurons in biceps brachii versus triceps brachii. J Neurophysiol 113:3692-3699.

Witham CL, Fisher KM, Edgley SA, Baker SN (2016) Corticospinal inputs to primate motoneurons innervating the forelimb from two divisions of primary motor cortex and area 3a. J Neurosci 36:2605-2616.

Xu J, Ejaz N, Hertler B, Branscheidt M, Widmer M, Faria AV, Harran MD, Cortes JC, Kim N, Celnik PA, Kitago T, Luft AR, Krakauer JW, Diedrichsen J (2017) Separable systems for recovery of finger strength and control after stroke. J Neurophysiol 118: 1151-1163.

Zaaimi B, Edgley SA, Soteropoulos DS, Baker SN (2012) Changes in descending motor pathway connectivity after corticospinal tract lesion in macaque monkey. Brain 135:2277-2289.

Ziemann U, Ishii K, Borgheresi A, Yaseen Z, Battaglia F, Hallett M, Cincotta M, Wassermann EM (1999) Dissociation of the pathways mediating ipsilateral and contralateral motor-evoked potentials in human hand and arm muscles. J Physiol 518:895-906.

Zörner B, Bachmann LC, Filli L, Kapitza S, Gullo M, Bolliger M, Starkey ML, Röthlisberger M, Gonzenbach RR, Schwab ME (2014) Chasing central nervous system plasticity: the brainstem's contribution to locomotor recovery in rats with spinal cord injury. Brain 137:1716-1732. 